\title{
PerCursos
}

\section{Covid-19: memórias e acervos em construção}

\begin{abstract}
Resumo
Em meio aos confrontos entre aqueles que se negam a adotar práticas de isolamento social e os que respeitam as recomendações das instituições científicas no contexto da Covid-19, há uma série de iniciativas que buscam registrar a produção de narrativas de memórias sobre experiências proporcionadas pela pandemia. A partir de projetos desenvolvidos por instituições públicas e privadas, cujas abordagens variam entre as dimensões individuais e coletivas, selecionamos iniciativas para aprofundar os debates sobre direito à memória, acesso aos acervos como prática democrática e construção plural de representações sobre o presente tensionado por incertezas, traumas e esperanças.
\end{abstract}

Palavras-chave: memória; acervos; Covid-19.

\author{
Hilário Figueiredo Pereira Filho \\ Doutor em História pela \\ Universidade Federal do Estado \\ do Rio de Janeiro - Unirio. \\ Historiador do Instituto do \\ Patrimônio Histórico e Artístico \\ Nacional - IPHAN e Professor do \\ Mestrado Profissional do IPHAN. \\ Brasil \\ hilario.iphan@gmail.com \\ orcid.org/0000-0003-1114-9719
}

\author{
Luana Xavier Ottoline \\ Licenciada em História pela \\ Universidade Federal do Estado \\ do Rio de Janeiro - Unirio. \\ Bacharel em Relações \\ Internacionais pela Universidade \\ Federal do Rio de Janeiro - UFRJ. \\ Brasil \\ ottoline.luana@gmail.com \\ orcid.org/0000-0003-2997-5373
}

\footnotetext{
Para citar este artigo:

PEREIRA FILHO, Hilário Figueiredo; OTTOLINE, Luana Xavier. Covid-19: memórias e acervos em construção. PerCursos, Florianópolis, v. 22, n.49, p. 252 - 276, maio/ago. 2021.
}

DOI: $10.5965 / 1984724622492021252$

http://dx.doi.org/10.5965/1984724622492021252 


\title{
Covid-19: memories and collections under construction
}

\begin{abstract}
Amidst the confrontations between those who refuse to adopt practices of social isolation and those who respect the recommendations of scientific institutions in the context of Covid-19, there are a series of initiatives that seek to record the production of narratives of memories about experiences provided by the pandemic. Based on projects developed by public and private institutions, whose approaches vary between individual and collective dimensions, we selected initiatives to deepen debates on the right to memory, access to collections as a democratic practice and plural construction of representations about the present tensioned by uncertainties, traumas and hopes.
\end{abstract}

Keywords: memory; collections; Covid-19. 


\section{Fazemos todos parte desta história Mesmo que os tontos blefem com a morte Num jogo de verdades e mentiras Um jogo duplo de azar e sorte (BUARQUE, Chico; GIL, Gilberto, 2020) ${ }^{1}$}

A declaração de pandemia da Covid-19 em 11 de março de 2020, por parte da Organização Mundial de Saúde (OMS), trouxe impactos significativos em todo mundo. Apesar da transmissão do novo coronavírus já ser uma realidade enfrentada por vários países quando do comunicado da agência da Organização das Nações Unidas (ONU), o efeito declaratório trouxe a sensação de que vivemos um tempo disruptivo. Ainda que cada indivíduo e grupo social conceba a doença de forma diferente - desde os significados construídos em torno da representatividade da Covid-19, passando pelas condições de enfrentar seus sintomas em caso de enfermidade, além da decisão de proteger a si próprio e os outros em um contexto de emergência sanitária -, é possível afirmar que as mudanças abruptas e repentinas nas vidas das pessoas consistem na faceta mais marcante das últimas décadas. Por ser um tipo de experiência inédita no século XXI, cujas proporções do trauma coletivo ainda não são dimensionadas, a Covid-19 revela-se como espécie de evento fundante (SCHWARCZ, 2020) que já traz marcas indeléveis para as vidas das pessoas em uma escala mundial.

Concomitantemente à disseminação do coronavírus, houve o alastramento de informações acerca da doença através dos mais variados meios de comunicação - sites, programas de televisão e rádio, revistas e jornais impressos, além dos conteúdos digitais produzidos e compartilhados por milhões de usuários nas redes sociais. Se por um lado percebe-se a importância das trocas comunicacionais como ferramentas democráticas de socialização do conhecimento científico, por sua vez, as mídias atuais podem ser veículos de muita desinformação. A saturação de referências à Covid-19 transformou a mesma em uma espécie de infodemia, fenômeno qualificado como aumento exponencial de notícias falsas acerca de determinado assunto. A desinformação pode afetar a saúde física e mental dos indivíduos, além de ser um desserviço para aqueles que trabalham

\footnotetext{
${ }^{1}$ SOB Pressão. Intérpretes: Chico Buarque e Gilberto Gil. Compositores: Chico Buarque e Gilberto Gil. 2020. O videoclipe da música pode ser acessado através do canal oficial de Gilberto Gil no YouTube. Disponível em: https://www.youtube.com/watch?v=M3l55HTBVPs. Acesso em 12 ago. 2021.
} 
diretamente na luta contra um vírus altamente contagioso e de consequências ainda não muito conhecidas (OPAS, 2020).

Além das dificuldades advindas pela situação da pandemia, a qual explicitou os profundos contrastes sociais e econômicos entre os países e as situações internas de cada um deles, a crise se mostrou presente no negacionismo que perpassa as esferas da ciência e da política. Há aqueles que seguem e adotam recomendações de instituições científicas, enquanto outros desconsideram protocolos mundiais e fomentam práticas negacionistas. O papel assumido por agentes políticos que corroboram a minimização e a negação da pandemia repercute nas práticas irresponsáveis em ambientes públicos e privados; tal postura é, por sua vez, seguida por outros que se sentem autorizados e incentivados a cometer o mesmo tipo de negligência².

Coletar e sistematizar falas dos negacionistas consiste em um ótimo instrumento para que não se esqueçam os discursos e ataques à ciência, ambos permeados pela necropolítica (MBEMBE, 2018) que se faz presente no contexto traumatizante da pandemia. A necessidade de guardar esses tipos de registros, ainda que afrontosos ao bem-estar geral, mostra-se como uma espécie de justa memória (RICOEUR, 2010) diante de um trauma coletivo. A explosão de informações e de fake news nas mídias digitais pode oferecer fontes de pesquisa relevantes sobre o momento dramático em que estamos imersos. As análises atuais e futuras acerca da Covid-19 serão fundamentais para um entendimento das construções das nossas memórias que ocorrem em meio aos conflitos e às disputas de narrativas - que podem estar respaldadas ou não pela dimensão do compromisso com a veracidade dos fatos.

É possível pensar que o negacionismo se apresenta como estratégia limite que aposta no silenciamento da pandemia, ao passo que os projetos de coletas de depoimentos são meios legítimos de preservar o direito às memórias individuais e

\footnotetext{
${ }^{2}$ A plataforma YouTube removeu 15 vídeos produzidos e compartilhados no canal oficial do presidente do Brasil, Jair Messias Bolsonaro, no dia 21 de julho de 2021, que veiculavam informações a respeito da Covid19. De acordo com o YouTube, o referido canal difundiu vídeos que apresentam riscos graves à saúde pública, pois reforçam uma série de inverdades acerca da pandemia: além de defender a falácia de que os medicamentos hidroxicloroquina e ivermectina funcionam como tratamento precoce da doença, tenta deslegitimar a eficácia científica comprovada de vacinas, além de desincentivar o uso de máscaras e a prática do isolamento social como medidas eficazes no combate à propagação do coronavírus.
} 
coletivas. Inspirados em iniciativas coletivas que coletaram testemunhos de eventos traumáticos como o 11 de Setembro de 2001 e o Furacão Katrina, em 2005, os projetos de memórias sobre a Covid-19 proliferaram de maneira contundente por todo mundo (MARINO; SILVEIRA; NICODEMO, 2020, p. 96-97)33. A ideia de incentivar a construção de documentos a partir de olhares e vivências de pessoas que, repentinamente, precisaram se isolar do convívio social e, por consequência, criaram novos cotidianos a que não estavam acostumados, propiciou a emersão de novas fontes de informações, as quais passarão a ser geridas por instituições públicas e privadas. Inspiradas pelo princípio de que os acervos são concebidos e gestados democraticamente, as iniciativas de mapear a Covid-19 pelo mundo abrem um flanco para problematizarmos as dimensões sociais dos acervos e das memórias como instrumentos políticos em prol de uma sociedade mais justa, democrática e plural.

\section{Mapeamento de iniciativas sobre as memórias da Covid-19}

O contexto da pandemia alterou sobremaneira o funcionamento das instituições de memória. Acostumadas ao trabalho presencial, boa parte precisou se reestruturar em termos logísticos e da dinâmica dos trabalhos com seus agentes; além disso, a situação de excepcionalidade levou muitas a problematizarem a nossa própria “nova realidade". E foi justamente a intenção de mapear quais instituições passaram a registrar as memórias na e sobre a pandemia que nos mobilizou quando do processo inicial de estruturação do presente artigo. Passamos, então, a investigar projetos por meio de redes sociais e sites de busca. De imediato, encontramos um mapa desenvolvido e alimentado por organizações de história pública com o compromisso de apontar as iniciativas de registro da Covid-19 em diversos países ${ }^{4}$. A partir dessa representação cartográfica temática para os dias atuais, iniciamos um levantamento de forma que pudéssemos analisar a relação

\footnotetext{
3 Os autores destacam que a Covid-19 traz maiores impactos para a sociedade mundial como um todo, tanto sincronicamente como assincronicamente nas experiências do isolamento social. Além disso, a intensidade dessas vivências é superior se comparada aos atentados de 11 de setembro, pois "no caso da pandemia somos todos vítimas desse evento global, agentes de sua realização, e não apenas suas testemunhas" (MARINO; SILVEIRA; NICODEMO, 2020 apud KEATING, 2020).

${ }^{4} \mathrm{O}$ mapa elaborado com as iniciativas está disponível em https://ifph.hypotheses.org/3225, consultado em $15 / 12 / 2020$.
} 
desses projetos com as instituições, a ideia de direito à memória e o contexto traumático em que vivemos.

Elaborado pelas organizações Made by Us e International Organization for Public History desde abril de 2020 e suscetível a constantes atualizações, o mapa lança um olhar sobre algumas iniciativas de coleta de experiências e documentação relativas à Covid-19 a partir do referencial de duas instituições norte-americanas. Considerando sua missão finalística, é possível sumarizar que a organização Made by Us busca promover o conhecimento histórico para jovens, em parceria com instituições âncoras ${ }^{5}$. Já a International Federation for Public History procura viabilizar conexões internacionais entre historiadores e incentivar uma rede mundial de pesquisadores de História Pública6.

Ambas as organizações são projetos de história pública e têm como finalidade difundir o estudo da história para um público para além da academia. A história pública é um campo diverso que busca expandir e popularizar o trabalho por meio dos arquivos, museus, fotografia, cinema, história oral, estabelecendo conexões com o conhecimento produzido na universidade, sem perder o compromisso com a produção de saberes, estimulando uma história mais participativa e colaborativa. O conceito e o debate sobre a história pública tiveram origem nos anos 1970, primeiramente na Inglaterra, expandindose para outros países. A prática da história voltou-se para a valorização de identidades coletivas e a divulgação de um conhecimento histórico organizado e mediado por conhecimentos locais. Nos Estados Unidos, a reflexão passou a ser sobre o uso público da história, fazendo o debate se ampliar. Ademais, novas preocupações surgiram sobre o processo de produção de fontes e de como atender a um público potencialmente mais diverso (DE ALMEIDA; ROVAI, 2013).

Formada por organizações voltadas para a história pública e privada - como o Museu Nacional de História Americana, Fundação Nacional de Arquivos e Museu de História de Miami -, a Made by Us tem a concepção de trabalhar coletivamente a fim de apresentar a história de maneira mais convidativa aos jovens, entendidos como agentes fundamentais para impulsionarem o futuro. A International Federation for Public History

\footnotetext{
${ }^{5}$ Disponível em: https://historymadebyus.com/who-we-are/, consultado em 28/09/2020.

${ }^{6}$ Disponível em: https://ifph.hypotheses.org/sample-page, consultado em 28/09/2020.
} 
(IFPH) foi criada em 2009 como uma força-tarefa da National Commission for Public History, tornando-se comissão interna do International Committee for Historical Sciences em 2010, organização não governamental voltada para promover as ciências históricas por meio da cooperação internacional; entre 2011 e 2012, transformou-se em Federação Internacional. Indivíduos, sociedades, institutos e programas, bem como outras organizações com atividades de história pública, podem se tornar membros da Federação. Além disso, possui um comitê diretivo e realiza assembleias gerais anualmente. Dentre os filiados, estão programas de universidades nos Estados Unidos, Austrália, Colômbia, Coreia do Sul e Itália.

Após o levantamento dos projetos identificados pela Made by Us e pela IFPH, optamos por analisar as iniciativas a partir da região continental em que estão e do tipo de instituição ou coletivo responsável, como os dados foram coletados, se há disponibilidade de acesso aos documentos coletados, e se apresentam um recorte temático para coleta das experiências. Foi possível identificar em todo o mundo 342 iniciativas, abarcando todos os continentes, com exceção da América Central e da África, os quais não possuem projetos apontados no mapa?.

A América do Norte foi a região com maior número de iniciativas, somando 241. Na Europa foram 75, na América do Sul 13, enquanto a Ásia e Oceania somam 12. A Made by Us, que é estadunidense, ficou responsável por reunir as iniciativas dos Estados Unidos, enquanto a IFPH pelo restante do mundo. É possível atribuir o desequilíbrio por região à nacionalidade da organização Made by Us, que pode cobrir sozinha as iniciativas do seu país de origem, prevalecendo um recorte ocidental do mapeamento.

Como proposta metodológica de análise do mapa, decidimos classificar e enquadrar as entidades em arquivos, bibliotecas, centro de pesquisa, museus, sociedades históricas e universidades. O termo arquivo foi usado para abarcar tanto as instituições de gestão de acervos arquivísticos, como locais que aglutinam coleções de documentos, sejam de origem particular ou pública. Por biblioteca, entendemos tanto as públicas quanto as universitárias. Os centros de pesquisa são aqueles voltados a fazer investigação

\footnotetext{
7 Nosso recorte tem como limite temporal o mês de novembro de 2020. O mapa analisado é dinâmico e pode incorporar novas iniciativas não cotejadas no número de 342 iniciativas identificadas.
} 
e divulgação científica, sem vínculos com universidades; enquanto estas são instituições de ensino e pesquisa constituídas por um conjunto de faculdades e escolas destinadas a promover a formação profissional e científica de pessoal de nível superior, e a realizar pesquisa e divulgação, contando com laboratórios e grupos especializados. As sociedades históricas aparecem principalmente nos Estados Unidos e são organizações que procuram preservar e promover o interesse na história de uma região, um período, ou temática. São tipicamente voltadas para um estado ou comunidade e oferecem coleções de artefatos, livros e testemunhos.

Ao se lançar um olhar panorâmico para o mapa concebido pela IFPH e pela Made by Us, é possível estabelecer alguns recortes a partir desses tipos de entidades. Entre as iniciativas de coleta de experiências na América Sul e do Norte, a maior parte delas é de museus (94), seguidos dos arquivos (51) e das sociedades históricas (49). Há ainda registro de bibliotecas (37), universidades (26) e centros de pesquisa (1). No continente europeu, prevalecem as iniciativas de arquivos (28), seguidos de museus (26), universidades (15), bibliotecas (4) e centros de pesquisa (4). Já na Ásia e na Oceania encontramos uma distribuição mais equilibrada: museus (4) coletando iniciativas, depois as bibliotecas (3) e universidades (3), por fim os arquivos (2).

A documentação é coletada principalmente através de formulários digitais, e-mail e redes sociais. Estas últimas são bastante utilizadas tanto para recebimento quanto para mobilização e divulgação dos projetos. As ações ocorrem em sua totalidade de forma virtual, considerando as medidas de distanciamento social. Com relação ao tipo de material recebido, as instituições adotaram formas bastante variadas, entre fotografias, textos, vídeos e áudios, possibilitando um conjunto complexo de fontes de caráter testemunhal sobre a pandemia. O conteúdo textual compõe $85 \%$ das formas de coleta, sendo a maneira mais usada pelas instituições. Porém, grande parte das instituições, em torno de $73 \%$, utilizam mais de uma forma de receber as experiências da pandemia, como materiais iconográficos e audiovisuais. Objetos também foram recebidos, primeiramente em forma de fotografias, para posterior exposição com o fim do período de isolamento.

Algumas delas também coletam material eletrônico, considerando o aumento da produção de dados na internet e das formas de convivência virtual. As iniciativas da 
Biblioteca Nacional da Austrália e a Biblioteca Nacional Francesa são alguns dos exemplos de coleta de websites. O Reino Unido, por exemplo, tem um arquivo chamado UK Web Archives voltado especificamente para essa finalidade. É uma colaboração entre seis bibliotecas britânicas que todo ano mapeiam, reúnem, preservam e dão acesso ao material disponibilizado em sites, formando coleções temáticas sobre eventos importantes, questões e áreas de interesse, como o Brexit, as mudanças climáticas e a pandemia do Covid-19.

A metodologia utilizada pelas instituições também foi um aspecto analisado na presente pesquisa. Definimos como "livre" o procedimento daquelas que não utilizaram nenhuma maneira específica para recebimento da documentação. Outros meios aplicados foram a formulação de questionários e as entrevistas feitas por agentes das instituições. Os questionários foram importantes para traçar perfis daqueles que contribuíram. Apesar da diversidade de métodos para conservar testemunhos, essas iniciativas apresentam em comum o fato de que os documentos são fornecidos de forma espontânea e voluntária, ou seja, o próprio público escolhe o que compartilhar. O questionário e as entrevistas podem, através das perguntas, delimitar a informação coletada e direcionar o testemunho.

No entanto, apenas 59 instituições disponibilizam digitalmente a documentação registrada em seus sites. O momento ainda é de recolhimento dos documentos e testemunhos, mas o compromisso com a acessibilidade parece ser algo compartilhado pela grande maioria das iniciativas. Num futuro próximo, essas instituições terão de pensar estratégias e meios de promover a acessibilidade. Os acervos digitais são uma tendência e, pensar, constantemente, em ferramentas de ampliação de acesso a documentos por um público mais diverso e plural ou de regiões mais periféricas, tanto em escala global quanto nacional, passa a ser um dos objetivos principais das iniciativas de mapear as experiências da Covid-19.

Muitas instituições, por serem locais ou por se responsabilizarem pela gestão de memórias de grupos sociais específicos, dedicaram-se a fazer um recorte temático na coleta de documentação. Os projetos se restringiram a comunidades locais, étnicas, institucionais e profissionais, além de recortes por idade e gênero. $O$ foco em 
comunidades locais prevaleceu em todas as regiões. Normalmente, essas comunidades estão associadas às cidades ou a estados. Os recortes profissionais estão voltados para os setores da saúde - médicos, enfermeiros, professores, pesquisadores e prestadores de serviços de limpeza, administração e segurança de hospitais - que passaram por mudanças bruscas em seus trabalhos e nas suas vidas particulares com as medidas de isolamento.

Considerando os dados levantados a partir do mapa da IFPH e da Made by Us, os Estados Unidos contabilizam o maior número de iniciativas no continente americano: 232 instituições arquivando documentação de todo o tipo para registro da pandemia, seguido por Canadá e Brasil, cada um com 9 iniciativas. Os museus também prevalecem como as instituições que recolhem histórias da pandemia nos EUA, além das sociedades históricas e de arquivos e bibliotecas universitárias. Por essa razão, a maior parte das iniciativas é local, devido aos museus e sociedades históricas representarem a memória de um estado ou região estadunidense em específico. A Sociedade Histórica de Vermont é um dos exemplos de iniciativas de documentar a pandemia do coronavírus em sua cidade, Vermont, formando um grande repositório digital com os testemunhos. No projeto Covid19 Archive - Images and stories from Vermont é possível submeter fotografias, vídeos e/ou textos com a intenção de mostrar as mudanças na rotina da comunidade. Dentre os testemunhos já disponíveis estão a imagem de um varal de máscaras de proteção, outra fotografia do primeiro dia de volta à escola com todos os cuidados sanitários e uma notícia sobre a volta dos turistas à cidade ${ }^{8}$.

O país é também o único a ter uma iniciativa de recorte por gênero. O projeto é do National Women's History Museum. O museu, voltado para histórias femininas, nasceu em 1995, nos Estados Unidos, após um grupo de mulheres iniciarem uma campanha para devolver a estátua em memória das sufragistas para a rotunda do Capitólio, seu local de origem. A instituição se dedica a destacar histórias de mulheres que transformaram os Estados Unidos. Com o início da pandemia, o museu incentivou mulheres a manterem um jornal com suas experiências durante esse período, a fim de capturar a voz feminina.

\footnotetext{
${ }^{8}$ O material recolhido está disponível no site da instituição: https://covid-19.digitalvermont.org/, acesso em 15/12/2020.
} 
É notório o maior impacto da pandemia na vida das mulheres, que precisaram lidar com as responsabilidades domésticas e conciliá-las com trabalho remoto. O peso de acompanhar aulas online dos filhos, os cuidados com familiares em vulnerabilidade e o desemprego caíram mais intensamente sobre a rotina das mulheres com a crise do coronavírus. Além disso, há a questão da violência, já que elas se encontram muito mais expostas aos agressores com o isolamento social e com maior dificuldade em denunciar. Essa iniciativa, então, é uma oportunidade de reunir relatos e memórias desse grupo, historicamente excluído das histórias oficiais. Os diários compartilhados serão expostos em exibições online e físicas a fim de contar as mudanças de rotina com a Covid-19 sob o ponto de vista das mulheres.

No Brasil, as universidades somam o maior número de iniciativas, representadas por laboratórios e grupos de pesquisa, tais como: "Memórias Covid19”, da Universidade Estadual de Campinas (Unicamp); “História oral na pandemia”, do Laboratório de História Oral e Imagem da Universidade Federal Fluminense (Labhoi/UFF); e "Amazônia em Quarentena”, do Núcleo de História Pública da Amazônia da Universidade Federal de Rondônia (Nuhpam/Unir). Em seguida, aparecem os arquivos públicos do sul e sudeste do país promovendo um registro participativo das memórias da pandemia. O Museu da Pessoa, que já nasceu voltado a uma formação de um acervo mais democrático, é o único representante dos museus no país com esse tipo de coleta de experiências na pandemia. Cabe reforçar, mais uma vez, que o rol dessas iniciativas e instituições voltadas para a documentação das memórias da Covid-19 se deu a partir daquelas identificadas pelo mapeamento da Made by Us e da IFPH.

O “Memórias Covid19" é um projeto online criado pela Unicamp, coordenado pela pesquisadora e historiadora Ana Carolina Moura Delfim Maciel. Através do site do projeto, é possível submeter experiências em diversos formatos como textos, áudios, imagens e vídeos, que serão selecionados e divulgados nas redes sociais nos próximos meses. A equipe curatorial conta com pesquisadores de diferentes áreas do conhecimento, como historiadores, escritores e profissionais da arte. O projeto busca coletar diferentes olhares sobre o momento de pandemia. 
Ao preencher o formulário para enviar a experiência, é necessário informar dados pessoais, sexo, faixa etária, ocupação, grau de escolaridade, se está passando o isolamento no Brasil ou exterior e se autoriza a divulgação do nome. O perfil daqueles que contribuíram, disponibilizado em gráficos na página do projeto em agosto de 2020, é em sua maioria feminino, do sudeste do país, formado principalmente por estudantes e funcionários públicos, com idade entre 41 e 50 anos. A ideia é coletar e preservar fragmentos de vivências e percepções para, segundo o "Memórias Covid19", buscar alternativas de novos horizontes e saídas para enfrentar um tempo futuro que é ainda bastante incerto.

O projeto do Arquivo Geral da Cidade do Rio de Janeiro teve início em maio de 2020. Voltado para moradores e trabalhadores da cidade do Rio de Janeiro, visa coletar testemunhos sobre a mudança de cotidiano dos cariocas durante a pandemia do Covid19. No entanto, com uma demanda de pessoas que residem fora do Rio de Janeiro, o projeto se abriu para contribuições de moradores de outras cidades.

Diferente das outras iniciativas no país, que deixam as contribuições mais livres, o projeto disponibiliza um questionário na plataforma Google Docs para ser respondido no site da instituição. As perguntas iniciais se referem ao perfil da pessoa, como idade, grau de escolaridade, em qual zona da cidade reside e em qual zona trabalha. As perguntas seguintes se referem ao isolamento social e como ele alterou a sua rotina e a das pessoas com quem convive. Há questões sobre idas ao mercado e farmácia, cotidiano de estudos, encontros com amigos e finanças pessoais. Também é possível anexar arte, poesia, fotografias, pinturas, vídeos produzidos durante o período de pandemia. É opcional a divulgação do nome e do e-mail para o depoimento.

A proposta do projeto "Arquivos da Pandemia", desenvolvido pela Casa de Oswaldo Cruz, da Fundação Oswaldo Cruz (COC/Fiocruz) é constituir um acervo de registros textuais, iconográficos, sonoros, audiovisuais que documente as múltiplas vivências dos membros da comunidade da Fiocruz em tempos de pandemia, e se estender para as comunidades do entorno da instituição. A Casa de Oswaldo Cruz é a unidade técnico-científica da Fiocruz dedicada à preservação da memória da instituição e às atividades de pesquisa, ensino, documentação e divulgação da história da saúde 
pública e das ciências biomédicas no Brasil. Com a pandemia, a Fiocruz ganhou ainda mais protagonismo no país como instituição científica voltada para a pesquisa de epidemias e de experiências na produção de vacinas.

O projeto fornece um questionário para perceber dimensões de experiências individuais nesse contexto, a vivência de trabalho e doméstica, sociabilidades e emoções. É necessário identificar a relação com a Fiocruz com garantia da condição de anonimato. O projeto tem como valores e princípios a participação, além de reforçar a identidade e memória institucional. Sob coordenação da historiadora e antropóloga Luciana Heymann, o "Arquivos da Pandemia" pretende trabalhar com as informações coletadas de forma a disponibilizá-las ao público de maneira crítica e sensível, respeitosa com os familiares de vítimas da pandemia, além de ser uma voz ativa contra o negacionismo que tenta sufocar a ciência e seus preceitos na contemporaneidade.

O Museu da Pessoa foi criado em 1991 e tem como objetivo contar histórias de vida de pessoas comuns, a fim de pluralizar as memórias e assim, construir uma barreira à intolerância. Em 1997, abriu seu espaço virtual para receber histórias pela internet. Adota uma metodologia de história oral e busca disseminar os conteúdos que produz para as comunidades, evidenciando questões e desafios, além da diversidade de identidades que podem ser contadas (MIZIARA, 2016, p. 237). O acervo já conta com mais de 18 mil histórias de vida de brasileiros, construído de forma colaborativa. Já com essa tradição participativa, durante a pandemia, o museu continuou recebendo de forma virtual essas memórias.

A temática da memória tem ganhado maior atenção pela historiografia num esforço de narrar experiências silenciadas ou esquecidas, especialmente ao estudar o tempo presente ou no campo da história oral, que busca valorizar subjetividades e experiências humanas; e também no campo da história pública. A memória de minorias tornou-se um meio de afirmação e reivindicação de identidade, forma de protesto e de justiça (NORA, 2009), culminando em maior discussão sobre a temática na esfera pública e na narrativa sobre o passado, o chamado "novo culto da memória" (TODOROV, 2000). 
As lembranças sobre situações traumáticas foram bastante evocadas, principalmente em função da "era da testemunha" (WIEVIORKA, 1998) de sobreviventes do holocausto nas últimas décadas do século XX, desdobrando-se para outras experiências, como a de presos políticos torturados nas ditaduras latino-americanas. Esses testemunhos abasteceram diversas coleções em todo mundo. A Fundação Shoah, por exemplo, produziu mais de 60 mil testemunhos de vídeo em mais de 30 línguas, segundo Wieviorka (1998). Eventos traumáticos mais recentes, como o 11 de setembro de 2001, foram simultaneamente registrados, dando origem a acervos digitais nos Estados Unidos, como acontece com a pandemia do Covid-19.

Em muitos momentos, o trauma - que podemos entender como uma consequência de "uma situação estressante de natureza excepcionalmente ameaçadora, dolorosa ou catastrófica" (SACRAMENTO, 2018) - pode ser um obstáculo na transmissão de um evento, esvaziando narrativas. Os acervos, depoimentos e testemunhos funcionam, então, como meio de restaurar processos que podem ainda ser lembrados e representados na narrativa histórica em suas experiências de dor, medo e esperança. Nesse sentido, as iniciativas de formar acervos digitais sobre a pandemia podem ser uma alternativa para lidarmos com as memórias sensíveis e traumáticas produzidas por esse presente estendido, marcado pelo luto. Esses acervos também podem posteriormente tornar-se ferramentas de discussões, uma vez que a pandemia pode ser encarada como “trauma cultural”, conceito aplicado por Eyerman (2004), quando algumas situações do passado são reencenadas no contemporâneo e continuam afetando a sociedade coletivamente.

Além disso, esses projetos podem ser uma forma de fortalecer a relação entre as instituições de memória e a comunidade em que estão inseridas, uma vez que as pessoas podem se sentir parte da construção das histórias sobre a Covid-19. Os acervos produzidos dentro desse contexto assumem papéis protagonistas: como uma forma de intervenção social, uma prática social participativa, o que torna o acervo um projeto coletivo e interativo, apresentando novas oportunidades de construção da memória coletiva (PINCHEVISKI, 2011, p. 256). Principalmente entre aqueles grupos sociais mais afetados pela quarentena e que se mostraram mais vulneráveis em função da pandemia, 
como mulheres, idosos e moradores de periferia. Segundo Boaventura de Sousa Santos (2020, p. 15), "qualquer quarentena é sempre discriminatória" e por isso a relevância de observar a pandemia também sob a perspectiva desses grupos.

\section{Ocupar arquivos com olhares interdisciplinares}

Consolidada como saber científico ao longo do século XX, a Arquivologia reúne uma variedade de manuais para a lida cotidiana com os acervos documentais. Em meio aos embates e conflitos típicos dos processos de constituição de campos do conhecimento (BOURDIEU, 1983), alguns conceitos aglutinam versões consensuais que se repetem nas publicações técnicas. A noção de documento é, por exemplo, qualificada por categorias como suporte, que abrange uma variedade de tipos (papel, disco magnético, meio eletrônico) sobre os quais se registram informações; gênero, que abarca a classificação de documentos audiovisuais, iconográficos e textuais; e espécie, termo que contempla uma miríade de exemplos como ata, certidão, parecer, fotografia e relatório. Para além das definições consagradas pelo saber arquivístico, o documento hoje é objeto analítico para filósofos, antropólogos, historiadores e cientistas sociais; ademais, abrem-se possibilidades de ser apropriado a partir de diferentes perspectivas tanto pela sua forma como através do conteúdo e da representatividade que assume na cena pública.

Isso não significa afirmar que a Arquivologia ignora uma postura crítica quanto à formação dos acervos arquivísticos e respectivas instituições custodiadoras que são, fundamentalmente, constituídos pela matéria-prima documental. Pelo contrário, assinalase a publicação de manuais que destacam a dimensão política dos documentos no contexto atual de demandas sociais em prol de uma diversidade de sujeitos e grupos historicamente pouco atendidos pelo Estado. Evidenciar os arquivos públicos enquanto instrumentos fundamentais para a comprovação de direitos individuais e coletivos, além de qualificar os documentos como registros de memórias fomentados socialmente são passagens presentes em manuais de tratamento de acervos arquivísticos. O léxico dessas publicações mobiliza termos como "fortalecimento da democracia e o pleno exercício da 
cidadania" (BERNARDES, 2008, p. 6), qualificando os arquivos como espécies de ágoras da contemporaneidade.

A abertura da Arquivologia para um diálogo mais conectado com a sociedade veio de forma paulatina, suscetível a recuos e avanços que oscilam a depender de cada país. Através de uma melhor estruturação do saber arquivístico como área do conhecimento, os arquivos passaram a ser tratados como objetos de reflexão sociocultural. A produção arquivística canadense é exemplo dessa postura mais crítica com os acervos documentais: profissionais foram instigados a rediscutir o papel social das instituições, os preceitos da atuação ética do arquivista e documentalista, além de se posicionarem na mudança de atitude quanto ao direito à informação por parte dos cidadãos em meados da década de 1990 (DURANTI, 1994, p. 50). No Brasil, interessa sublinhar o processo que culminou na promulgação da conhecida "Lei de Arquivos"9 como instrumento jurídico responsável por balizar a aproximação da sociedade brasileira com documentos públicos e privados, em consonância com o processo de redemocratização após a ditadura civilmilitar de 1964-1985.

Uma marcante contribuição canadense para os estudos técnicos da Arquivologia internacional consiste na noção de "arquivo total". Ao invés de meros guardiães de documentação comprobatória do Estado, os arquivos públicos representam, potencialmente, um amplo repertório de possibilidades que tocam em questões identitárias, históricas, sociais e das memórias individuais e coletivas dos diferentes agentes e grupos. A explosão documental, característica da segunda metade do século XX, foi bastante marcante e trouxe no seu bojo demandas por tratamento e de constantes reflexões epistemológicas. Se pensarmos que a produção de documentos cresce exponencialmente com o suporte digital, em especial nas últimas décadas, a ideia de "arquivo total" assume contornos ainda mais significativos. Ao realizar uma leitura retrospectiva de paradigmas que constituíram a disciplina arquivística, Terry Cook destaca

\footnotetext{
9 Trata-se da Lei Federal $n^{\circ}$ 8.159, de 1991, regulamentada pelo Decreto $n^{\circ} 4.553$, de 2002, que propõe diretrizes para a gestão de arquivos no país. Fruto do amadurecimento de questões que foram debatidas no processo de redemocratização brasileira nos anos 1980, a "Lei de Arquivos" é considerada por especialistas como de perfil técnico, trazendo eixos norteadores como gestão documental, preservação e acesso aos arquivos, além da criação do Conselho Nacional de Arquivos (Conarq).
} 
a atuação do Arquivo Nacional do Canadá, em especial através do profissional Hugh Taylor, como pioneira no tratamento epistemológico dos documentos nascidos digitais:

Taylor veio da Inglaterra para o Canadá em 1965 e foi cedo influenciado pelas teorias sobre comunicação e mídia dos canadenses Harold Innis e Marshall McLuhan. Em breve começou a aliar uma aguda percepção do caráter transformador dos novos documentos audiovisuais e eletrônicos e do imenso poder das tecnologias da comunicação global a uma profunda visão ecológica, holística e espiritual. Com essa potente combinação, Taylor livrou muitos arquivistas canadenses e internacionais de seu 'desvio histórico' de pesquisar antigos documentos e instalou-os firmemente na era da informação dos documentos eletrônicos, das redes de comunicação global, das preocupações comunitárias locais com seu patrimônio, e das iniciativas biorregionais. Assim conseguiu ele relativizar o sentido de contextualidade (ou proveniência) dos documentos, investigando as ricas interconexões entre a sociedade e o registro documental, entre o ato e o documento. (COOK, 2018, p. 46-47)

Interessante frisar que Taylor provocou os arquivistas a pensarem para além das lógicas estritamente arquivísticas, uma vez que os contextos dos documentos podem e dever ser lidos a partir de diálogos com outras disciplinas de conhecimento, em consonância com os diferentes contextos históricos. Nessa medida, o formato digital dos documentos, cada vez mais hegemônicos na contemporaneidade e, no contexto da Covid-19, maciçamente produzidos por pessoas sob as circunstâncias de confinamento, é um excelente exemplo de como a forma influencia o conteúdo numa relação de reciprocidade. A produção e a leitura dos documentos digitais ganham um amplo espectro com os signos empregados nas suas construções: a partir de aparelhos portáteis como um simples smartphone, as linguagens audiovisuais, textuais e sonoras podem trazer visões de mundo daqueles que produzem todo e qualquer tipo de documento acessível através das telas dos dispositivos. Apreender um documento do tempo presente ganha espaço substancial nas reflexões daqueles que podem ser chamados de artífices da memória, não limitado aos arquivistas, mas também os profissionais como jornalistas, cientistas sociais, historiadores, dentre outros. 
O interesse da Antropologia e da Filosofia pelos arquivos foi fundamental para a consolidação de um olhar interdisciplinar na área. As contribuições de autores referenciais como Michel Foucault e Jacques Derrida mostraram-se decisivas para a emersão de novos olhares menos tecnicistas e mais problematizadores dos documentos como representações de uma pretensa verdade. Ao abordar as obras dos referidos filósofos, Luciana Heymann salienta que ambos pensaram o arquivo como local simbólico aglutinador de memórias, saber e poder, dotado de significância política que consegue moldar a informação daquilo que pode ser dito e silenciado. As contribuições instigantes de Derrida e Foucault foram fundamentais para abrirem os arquivos para novas reflexões, as quais proporcionaram aos acervos documentais a capacidade de serem "configuradores do real" a partir dos mais variados pontos de vistas, sem se limitarem à tradicional ideia de serem simples depósitos de registros das instituições (HEYMANN, 2012, p. 24).

A guinada antropológica dos arquivos é marcante a partir dos anos 2000. Ainda que a área documental testemunhe concepções alinhadas a uma pretensa tecnicidade nos dias atuais - como se os tratamentos de acervos fossem ilesos a qualquer tipo de decisão política, administrativa e social -, nota-se que o diálogo interdisciplinar se firmou como eixo referencial nas problematizações acerca do documento agenciado nas construções das memórias. A mescla entre as perspectivas antropológica e arquivística se apresenta como recurso metodológico para compreensão dos arquivos: "No fundo, ambas se ocupam de representações - de pessoas, de culturas, de fatos e, em última instância, de história e de memória. Ambas exercem poder na criação e uso de documentos, observações, informação" (KAPLAN, 2018, p. 179). Os sentidos e significados atribuídos aos arquivos oscilam conforme as variantes sociais, políticas e culturais engendradas em meio a disputas de poder que definem aquilo que é salvaguardado para o futuro. Conceber os arquivos como objetos reflexivos a partir de olhares múltiplos mostra-se, pois, como tendência que articula diferentes saberes intercambiáveis e complementares.

Dentre as concepções de acervo nutridas pela interdisciplinaridade, sublinha-se que cada arquivo pode ser problematizado a partir de uma trajetória biográfica - assim 
como estudos da Museologia investem na investigação das peças de determinado museu (ROQUE, 2013). A proposta de desnaturalizar o processo de constituição de um acervo como algo dado, neutro e atemporal auxilia a pensar que documentos gerados sobre a Covid-19 dialogam com o contexto em que estamos imersos. Os acervos que se formaram ou estão em processo de constituição nas instituições de memória, através dessa experiência coletiva traumática, podem trazer reflexões sobre as representatividades da pandemia sob diferentes recortes sociais. A perspectiva antropológica de que os arquivos são construções históricas e que suscitam reflexões de cunho político, social, cultural a respeito das circunstâncias de suas respectivas criações e dos seus posteriores acessos é fundamental para desnaturalizarmos os mesmos como meros repositórios de informações (HEYMANN, 2012, p. 20).

A construção de acervos sobre a Covid-19 mostra-se como objeto passível de reflexões acerca da representatividade dos documentos. Afinal, o que os acervos gerados na e sobre a maior pandemia dos últimos séculos podem significar? Em artigo ensaístico em que traz a plástica frase "a história pode ser um romance, mas o arquivo é uma poética" (LISSOVSKY, 2004, p. 47), Maurício Lissovsky sumariza cinco facetas para a compreensão dos arquivos. A primeira delas consiste na dimensão historiográfica, fruto do projeto iluminista de proteger os acervos documentais da ação inexorável do tempo, tendo nos arquivos um dos símbolos modernos da resiliência em prol do conhecimento. O caráter republicano seria a tentativa de se evitar a apropriação do público e coletivo pelo privado. Já o viés cartorial cumpre a prerrogativa de proteger a sociedade das tentativas de mentira e fraude, respaldando-se na importância da autenticidade como garantia mínima dos fluxos de documentos. A dimensão cultual reside no compartilhamento de que o passado deve ser respeitado e, para isso, a ameaça permanente do esquecimento consegue ser atenuada com a criação de instituições como bibliotecas, museus e arquivos. E, por fim, a prerrogativa de abarcar a dimensão poética que, para além da aparente frieza dos ambientes em que os documentos se encontram dispostos, traz uma infinidade de possibilidades de criação e de fruição dos arquivos construídos a partir das mais variadas experiências humanas (LISSOVSKY, 2004). 
Nesses termos, pode-se afirmar que os acervos gerados no contexto da Covid-19, por diferentes indivíduos e grupos sociais têm o potencial de reunir as cinco dimensões destacadas - historiográfica, republicana, cartorial, cultual e poética -, na medida em que permitem colocar o direito à memória no centro das suas próprias constituições. Não é o propósito do presente artigo acessar e avaliar os conteúdos desses acervos em processo de gestação, apenas de apontar para possibilidades vindouras de fruição analítica. Produzir registros do presente com vistas a acessá-los num futuro próximo é uma das razões de ser dos acervos da pandemia. Calcado na ideia de que os arquivos se tornaram uma demanda social depois de muitos deles permanecerem inacessíveis, o direito à memória aciona argumentos indispensáveis para o exercício da nossa cidadania: nomeia os anônimos ao inscrevê-los na escrita da história, possibilita conceder um protagonismo àqueles que poderiam seguir ausentes, assim como permite abrir possibilidades de apropriações das vivências de agentes sem cair em mecanismos de esquecimento (SALOMON, 2011, p. 10). Registrar as impressões individuais acerca de um contexto de crise - seja esta de ordem sanitária, social, política e econômica -, pode ser uma forma de mapear as desigualdades que a pandemia desnuda explicitamente nas diferentes camadas da sociedade.

Por serem produzidos no contexto de isolamento social, muitas vezes voltados para uma perspectiva introspectiva, os registros reunidos pelas iniciativas de mapear as experiências da Covid-19 são de natureza digital. Dentre as ações citadas ao longo do texto, salienta-se que a maioria dos registros foram gerados a partir de equipamentos eletrônicos - ressaltamos, mais uma vez, que não é nossa proposta detalhar os formatos e conteúdos dos acervos gerados nas diferentes experiências. Se antes da pandemia os documentos digitais já eram uma tendência na contemporaneidade, o cenário atual é propício para que essa produção seja exponencialmente maior. Ainda que existam dificuldades de estender a acessibilidade às tecnologias digitais de forma mais democrática, as conexões possíveis entre as pessoas criaram uma explosão ainda maior de mensagens textuais, áudios, vídeos e chamadas simultâneas através de plataformas digitais. A velocidade intensa das formas de comunicação de base digital, se por um lado revela a sensação de ampla conectividade, por outro traz a impressão de que tudo é tão 
fluido que pode se desfazer e perder-se abruptamente (BAUMAN, 2011). Nessa medida, a intenção do registro de experiência seria uma forma de captar algo que fosse passível de guarda para uma fruição a posteriori.

Os documentos digitais são mobilizados em razão das suas potencialidades. Artefatos munidos de contornos e entornos sem limites rígidos, podem remeter a outros documentos por meio de infindáveis hiperlinks; além disso, a ideia do original acaba se esvaindo em razão da representação do digital alcançar outros sentidos, sendo possível pensar na reconstrução do documento a cada momento em que o mesmo for acessado por aplicativos através das telas de aparelhos eletrônicos. A ideia de o documento ser uma espécie de membrana que permite a absorção de valores sociais é qualificada de forma a transmitir uma fluidez constante: "Toda vez que um criador, usuário ou arquivista interage com o documento, intervindo, interrogando e interpretando, esse documento é construído de maneira ativa. Cada ativação deixa marcas no documento ou em seu contexto, as quais constituem os atributos da significação ilimitada dos arquivos" (KETELAAR, 2018, p. 197). Os novos tipos de agenciamentos a que os documentos estão suscetíveis assinalam uma "nova ecologia do escrito" (ARTIÈRES, 2011, p. 107), a partir da qual é possível pensar no próprio futuro dos arquivos enquanto constructos sociais que se interconectam com as possibilidades de se preservar memórias e tecer histórias para a posterioridade.

\section{Considerações finais}

Os testemunhos sobre a pandemia têm ajudado a lidar com o luto e as rotinas modificadas, mas a garantia do pleno direito à memória dessa crise vai depender de como as instituições vão tratar essa documentação e como será disponibilizada, de forma a permitir maior acessibilidade. Por essa razão, é importante reconhecer as potencialidades da produção de acervos digitais, em especial sobre a pandemia, quando a troca de informações e dados se intensificou nas redes. As iniciativas de acervos digitais permitem que a pandemia seja documentada a partir de múltiplos olhares e em diferentes linguagens. Mapear esses projetos também auxilia na garantia de maior acesso e 
divulgação, como fizeram as organizações Made by Us e IFPH, ao possibilitaram visualizar como se deram essas iniciativas em diferentes continentes, as instituições de memória participantes e como mobilizaram suas comunidades para coleta de testemunhos, além de demonstrarem a utilização mais ativa dos meios digitais nesse processo.

A crise da Covid-19 escancarou e agravou as desigualdades presentes relativas à etnia, classe e ao gênero. A oportunidade de documentar essas diferenças a partir de fontes voluntárias e espontâneas esclarece a função democrática das instituições de memória, de maior aproximação com a comunidade e de sua politização. Significam maior representatividade e mapeamento da incidência desigual da pandemia sobre grupos sociais vulneráveis. Com isso, é possível fazer reivindicações a partir desses testemunhos para exercício do direito e do dever de memória a fim de lidar com os traumas individuais e coletivos decorrentes do Covid-19.

Em meio às incertezas e disputas políticas que permeiam o contexto dramático da pandemia no Brasil, valorizar projetos de memórias sobre a Covid-19 em possíveis diálogos com iniciativas de outros países pode ser uma forma de nos fortalecer na luta contra o negacionismo histórico e científico. Além do importante trabalho de recolhimento de testemunhos realizado nos últimos meses, as medidas de tratamento dos acervos gerados, somadas às fruições dessas memórias em projetos de interface com o público serão de grande valia e ocuparão os debates interdisciplinares em um futuro próximo. Cabe a nós, enquanto pesquisadores, escrever uma história que não apague essas memórias difíceis e traumatizantes; narrativas plurais estas que são necessárias e fundamentais na nossa luta cotidiana como agentes em prol de um mundo melhor.

\section{Referências}

ARAÚJO, Maria Paula Nascimento; SANTOS, Myrian Sepúlveda dos. História, memória e esquecimento: implicações políticas. Revista Crítica de Ciências Sociais, Coimbra, n. 79, p. 95-111, 2007.

ARTIÈRES, Philippe. Monumentos de papel: a propósito de novos usos sociais dos arquivos. In: SALOMON, Marlon (org.). Saber dos arquivos. Goiânia: Edições Ricochete, 2011. p. 99-110. 
BAUMAN, Zygmunt. Modernidade líquida. Rio de Janeiro: Jorge Zahar Editor, 2011.

BERNARDES, leda Pimenta. Gestão documental aplicada. São Paulo: Arquivo Público do Estado de São Paulo, 2008. Disponível em:

http://www.arquivoestado.sp.gov.br/site/assets/publicacao/anexo/gestao_documental_a plicada.pdf. Acesso em: 23 jun. 2021.

BOURDIEU, Pierre. O campo científico. In: ORTIZ, Renato (org.). Pierre Bourdieu: sociologia. São Paulo: Ática, 1983.

COOK, Terry. O passado é prólogo: uma história das ideias arquivísticas desde 1898 e a futura mudança de paradigma. In: HEYMANN, Luciana; NEDEL, Letícia (orgs.). Pensar os arquivos: uma antologia. Rio de Janeiro: FGV Editora, 2018. p.17-82.

DE ALMEIDA, Juniele; ROVAI, Marta Gouveia. História pública: entre as "políticas públicas" e os “públicos da história”. In: SIMPÓSIO NACIONAL DE HISTÓRIA, 27., Natal. Anais [...]. Natal: ANPUH, 2013.p. 1-10.

DOS SANTOS, Myrian Sepúlveda. Memória coletiva, trauma e cultura: um debate. Revista USP, São Paulo, n. 98, p. 51-68, 2013.

DURANTI, Luciana. Registros documentais contemporâneos como provas de ação. Estudos Históricos, Rio de Janeiro, v. 7, n. 13, p. 19-67, 1994.

EYERMAN, Ron. Cultural Trauma: Slavery and the Formation of African American Identity. In: ALEXANDER, Jeffrey.; EYERMAN, Ron; GIESEN, Bernhard; SMELSER, Neil; SZTOMPKA, Piotr. Cultural trauma and collective identity. Berkeley: University of California Press, 2004. p. 60-111.

HEYMANN, Luciana. O lugar do arquivo: a construção do legado de Darcy Ribeiro. Rio de Janeiro: Contra Capa: Faperj, 2012.

KAPLAN, Elisabeth. Muitos caminhos para verdades parciais: arquivos, antropologia e o poder da representação. In: HEYMANN, Luciana; NEDEL, Letícia. (orgs.). Pensar os arquivos: uma antologia. Rio de Janeiro: FGV Editora, 2018. p. 177-192.

KETELAAR, Eric. (Des)construir o arquivo. In: HEYMANN, Luciana; NEDEL, Letícia. (orgs.). Pensar os arquivos: uma antologia. Rio de Janeiro: FGV Editora, 2018. p. 193-206.

KEATING, Joshua. Covid-19 is the first truly global event. Slate, Washington, 5 may. 2020. Disponível em: https://slate.com/news-and-politics/2020/05/covid-19-global-eventpandemic.html. Acesso em: 20 nov. 2020. 
LISSOVSKY, Maurício. Quatro + uma dimensões do arquivo. In: MATTAR, Eliana (org.). Acesso à informação e política de arquivos. Rio de Janeiro: Arquivo Nacional, 2004. p. 4763.

MARINO, Ian; SILVEIRA, Pedro; NICODEMO, Thiago. Arquivo, memória e Big Data: uma proposta a partir da Covid-19. Cadernos do Tempo Presente, São Cristóvão, v. 11, n. 01, p. 90-103, 2020.

MBEMBE, Achille. Necropolítica: biopoder, soberania, estado de exceção, política da morte. São Paulo: N-1 Edições, 2016.

MIZIARA, Rosana. Experienciar museus: um olhar sobre o Museu da Pessoa. Revista do Centro de Pesquisa e Formação, São Paulo, n. 2, p. 232-248, 2016.

NORA, Pierre. Memória: da liberdade à tirania. Revista Musas, Brasília, v. 2, n. 4, p. 6-10, 2009.

OPAS. Organização Pan-Americana da Saúde. Entenda a infodemia e a desinformação na luta contra a Covid-19. Página Informativa n. 5 da Organização Pan-Americana da Saúde OPAS: Organização Mundial da Saúde - OMS. [S.I.]: OPAS, 2020. Disponível em: https://iris.paho.org/bitstream/handle/10665.2/52054/FactsheetInfodemic_por.pdf?seques eq=14. Acesso em: 20 nov. 2020.

PINCHEVSKI, Amit. Archive, media, trauma. In: MEYERS, Oren; NEIGER, Motti; ZANDBERG, Eyal (ed.). On media memory. Londres: Palgrave Macmillan, 2011, p. 253-264.

RICOEUR, Paul. A memória, a história e o esquecimento. Campinas: Editora da Unicamp, 2010.

ROQUE, Ricardo. A circulação de histórias e coleções nos impérios coloniais. Poderes, saberes, instituições. In: JERÓNIMO, Miguel Bandeira (org.). 0 Império colonial em questão (Sécs. XIX-XX). Lisboa: Edições 70, 2013. p. 455-485.

SACRAMENTO, Igor. A era da testemunha: uma história do presente. Revista Brasileira de História da Mídia, São Paulo, v. 7, n. 1, p. 125-140, 2018.

SALOMON, Marlon. A danação do arquivo: ensaio sobre a história e a arte das políticas culturais. In: SALOMON, Marlon (org.). Saber dos arquivos. Goiânia: Edições Ricochete, 2011. p. 29-42.

SCHWARCZ, Lilia. Quando acaba o Século XX. São Paulo: Companhia das Letras, 2020. 
SOB Pressão. Intérpretes: Chico Buarque e Gilberto Gil. Compositores: Chico Buarque e Gilberto Gil. [S.I.: s.n], 2020. 1 vídeo. (4 min.). Disponível em:

https://www.youtube.com/watch?v=M3l55HTBVPs. Acesso em: 12 ago. 2021.

SOUSA SANTOS, Boaventura. A cruel pedagogia do vírus. Coimbra: Almedina, 2020.

TODOROV, Tzvetan; SALAZAR, Miguel. Los abusos de la memoria. Barcelona: Paidós, 2000.

WIEVIORKA, Annette. L’ère du témoin. Paris: HachetteLittératures, 1998.

Recebido em: 05/04/2021

Aprovado em: 05/08/2021

Universidade do Estado de Santa Catarina - UDESC

Centro de Ciências Humanas e da Educação - FAED

PerCursos

Volume 22 - Número 49 - Ano 2021 revistapercursos@gmail.com 